\title{
PLASMA $\alpha$-AMINO ACID NITROGEN AND SERUM LIPIDS OF SURGICAL PATIENTS
}

\author{
By EVELYN B. MAN, PATRICIA G. BETTCHER, CLAIRE M. CAMERON, AND \\ JOHN P. PETERS \\ (From the Departments of Psychiatry and Internal Medicine of the Yale University School of \\ Medicine, New Haven)
}

(Received for publication April 1, 1946)

In the plasma of patients who had acute infections or who had had injuries or operations, the concentration of $a$-amino acid nitrogen was usually within or below the normal range. The nitrogen metabolism of these patients was studied by Grossman, et al (1). Previously Farr and associates (2) had reported that the plasma $a$-amino acid nitrogen of children decreased immediately after nitrous oxide or ether anesthesia and operation. It seemed likely that such a reduction of amino acids might be a general reaction to injury, and that it might be connected with the nitrogen losses usually encountered in disease and after trauma (1, 3 ic: 5 ).

For this reason, the $a$-amino acid nitrogen of the plasma of 30 patients was measured in the postabsorptive state on the morning of the day of operation, the following morning, and on some subsequent morning in the course of recovery. In 10 . other patients plasma $a$-amino acid nitrogen was measured the morning after operation, and on some subsequnt morning during convalescence.

In addition, the serum lipids of 9 patients were measured on the morning of operation, and on 2 succeeding mornings.

\section{EXPERIMENTAL PROCEDURE}

Data included in this paper were collected from patients who were studied to learn the immediate effects of injury upon nitrogen metabolism. Operation was chosen because it permitted observations to be made both before and after injury. The exact plan of the experiments is given below, but the investigation followed work already described in detail (1). On the mornings of the day of operation, the day after operation, and some day 2 to 21 days following operation, blood was drawn from patients in the post-absorptive state, was placed in tubes with dry heparain and analyzed for plasma a-amino acid nitrogen by the method of Hamilton and Van Slyke $(6,7)$. Certain patients were not followed according to this regimen, but the changes are obvious in the table. Routinely, $0.1 \mathrm{mgm}$. was subtracted from the plasma amino acid nitrogen as a correction for the urea nitrogen. However, no further correction was made in the few instances in which the nonprotein nitrogen exceeded $40 \mathrm{mgm}$. per cent. In another article (8) data collected simultaneously are given, but these data do not relate quantitatively to the results included in this report. Blood nonprotein nitrogen, creatine and creatinine of serum were determined on the pre-operative and post-operative mornings. All the urine voided during these 2 days was collected and analyzed for total nitrogen, creatine and creatinine. All food and fluids taken by the patients during this period were measured and recorded. No attempt was made to control the treatment, which was left entirely to the surgeons in charge of the cases. In most instances the patients received only salt solution and small amounts of glucose during the first 24 hours, although certain patients were given transfusions. The nature of the operations with a few relevant remarks about the patients are given below.

A83628 M59. Cholecystectomy for chronic cholecystitis while patient was symptomless.

A44427 M68. Removal of gastric polyp. Operation 20 days after symptoms, brief hemorrhage, an obese patient. Recovery good. On regular diet 36 hours before last blood study.

B44458 F23. Excision of adenofibroma of breast under local anesthesia. Patient in good health.

B61691 M57. Reamputation of leg because of abscess in stump. Infection slight and condition of patient good.

B53965 F67. Cholecystectomy and removal of stone from common duct. Chronically ill and undernourished, slight icterus. Renal insufficiency with elevated nonprotein nitrogen. At last blood study still on soft diet. Not completely recovered.

B8104 M50. Gastrectomy for gastric ulcer. Epigastric distress relieved by meals. No hemorrhage or obstruction. Nutrition well maintained. At last blood study still on full liquid diet.

A44648 F36. Cholecystectomy for cholelithiasis in interval with patient well, quite obese. $\mathrm{Fe}$ brile at discharge, cause unknown. 
B62115 M36. Gastrectomy under spinal anesthesia for gastric ulcer. In good condition. Had severe hemolytic transfusion reaction. Still on full liquid diet at last date.

34340 F52. Repair of abdominal hernia. Condition excellent. Course uneventful.

A11178 F32. Cholecystectomy for cholelithiasis. Condition reported good. Developed infection of stab wound. Only 1 day on soft diet before last blood study.

90248 M69. Left inguinal hernioplasty. Condition excellent. Still on full liquid diet at last blood study.

B69089 F42. Abdominal perineal resection of carcinoma of rectum. Asymptomatic. Condition good. Still on soft diet at last blood study.

25165 F47. Hysterosalpingo-oöphorectomy for uterine myomata.

B68338 F42. Radical mastectomy for carcinoma of breast. General condition good. Stormy post-operative course for 1 week. Final amino acids after 2 days of improvement.

A10607 M34. Inguinal hernioplasty under local anesthesia.

B68027 M34. Inguinal herniorrhaphy. Patient had a carbuncle on his forearm that was incised on the following day.

A79194 F61. Block resection of fibrosarcoma of chest wall, recurrent. Patient had lost weight and had suffered considerably from the tumor. Slow, poor convalescence.

B62484 F37. Cholecystectomy and appendectomy for gall stones and acute appendicitis. Had intermittent fever and chills with almost continuous nausea and frequent vomiting for 10 days before operation. Still febrile and quite sick at time of last amino acid, thereafter satisfactory recovery.

B49302 M43. Excision of pulmonary cyst. Although reported well developed and nourished, he had suffered from severe dyspnea and chest pain for 3 months and had lost 26 pounds. Still quite sick at last blood study.

B59857 M51. Gastrectomy for gastric ulcer. For 2 months he had suffered with epigastric distress, anorexia, nausea, vomiting and tarry stools, and had lost 15 pounds.

61724 M17. Drainage of appendiceal abscess 15 days after onset of acute appendicitis. Still very sick. Eggnog mixture by stomach tube.

M61. Gastrostomy for esophageal carcinoma. Emaciated and chronically ill. Stormy post-operative state at time of last blood study.
B68658 F59. Cholecystectomy for cholelithiasis and chronic cholecystitis. Although obese she had suffered from symptoms continuously for 19 days before operation.

B69576 M70. Exploratory thoracotomy and gastrostomy for carcinoma of esophagus. Had lost 25 pounds.

B5775 M30. Resection of ileum, cecum, and ascending and transverse colon for enteritis. Also had pulmonary tuberculosis. Slow convalescence. Only 2 days on regular diet at last blood study.

B68445 M65. Resection of sigmoid for carcinoma 2 weeks after a cecostomy. Still quite stormy post-operative course at last blood study.

B61943 F46. Drainage of liver abscess which followed severe traumatic injury 3 months earlier.

34038 F35. Appendectomy, 11 hours after onset of acute appendicitis.

A94807 M66. Cholecystojejunostomy for carcinoma of duodenum. Had been jaundiced for 2 months and had lost much weight. Still quite sick at last blood study.

B68886 F52. Drainage of lung abscess, sequel to a pneumonia that began 19 days earlier. Convalescence satisfactory but slow.

A36925 M22. Appendectomy 48 hours after onset of abdominal pain and nausea. Normal appendix removed. Patient well developed and well nourished.

A49273 M48. Right inguinal hernioplasty under local anesthesia in an obese patient who had not been ill.

B56452 M18. Appendectomy 13 hours after onset of acute appendicitis in a well developed and well nourished patient.

B19794 M45. Ventral herniorrhaphy following satisfactory recovery after penicillin and excision of axillary abscess 17 days previously. Moderately obese.

B58111 M20. Appendectomy 24 hours following onset of acute appendicitis in a well developed and well nourished male.

B58721 M37. Herniorrhaphy after 10 year history of right inguinal hernia which had not interfered with strenuous muscular work. Nothing by mouth or parenterally during first post-operative day.

A3107 M53. Left inguinal herniorrhaphy in a well nourished patient with arteriosclerotic heart disease and earlier history of pulmonary fibrosis.

B57895 M52. Appendectomy 48 hours after onset of appendicitis with vomiting and ingestion of fluids only. Patient thin and had chronic bronchitis. Post-operatively wound in- 
fection developed and patient febrile for 7 days, after that good recovery.

91253 M25. Appendectomy 11 hours after acute onset of appendicitis. Well developed and very well nourished. Post-operatively febrile for 5 days with drainage from wound site. Six days later wound had healed and patient was discharged

B57836 M32. Stab wound in chest of a well developed, well nourished male. Following supportive treatment for shock, diaphragm and peritoneum were sutured. Bronchopneumonia developed, sulfadiazine given, wound continued to drain. Febrile course for 2 weeks followed by improvement.

\section{RESULTS}

Plasma $a$-amino acid nitrogen was measured by the same procedure $(6,7) 106$ times on 55 patients. Among these patients were most of the 45 patients studied by Grossman, Sappington, Burrows, Lavietes and Peters (1). About half of the 45 had medical conditions (meningococcus meningitis, pneumonia, scarlet fever, etc.) while the others had surgical conditions. In Figure 1 the post-absorptive concentrations of $a$-amino acid nitrogen in the plasma are compared with the nitrogen metabolim. There is obvious lack of correlation. Even when nitrogen catabolism and negative nitrogen balances were extremely large, plasma amino acid nitrogen was most frequently in the normal range or even below normal.

In Table $I$ are given the concentrations of $a-$ amino acid nitrogen in the plasma of surgical patients on the morning of the operation, and of the first post-operative day, and at various intervals thereafter. In the first column after the patients' numbers the physical conditions of the patients at

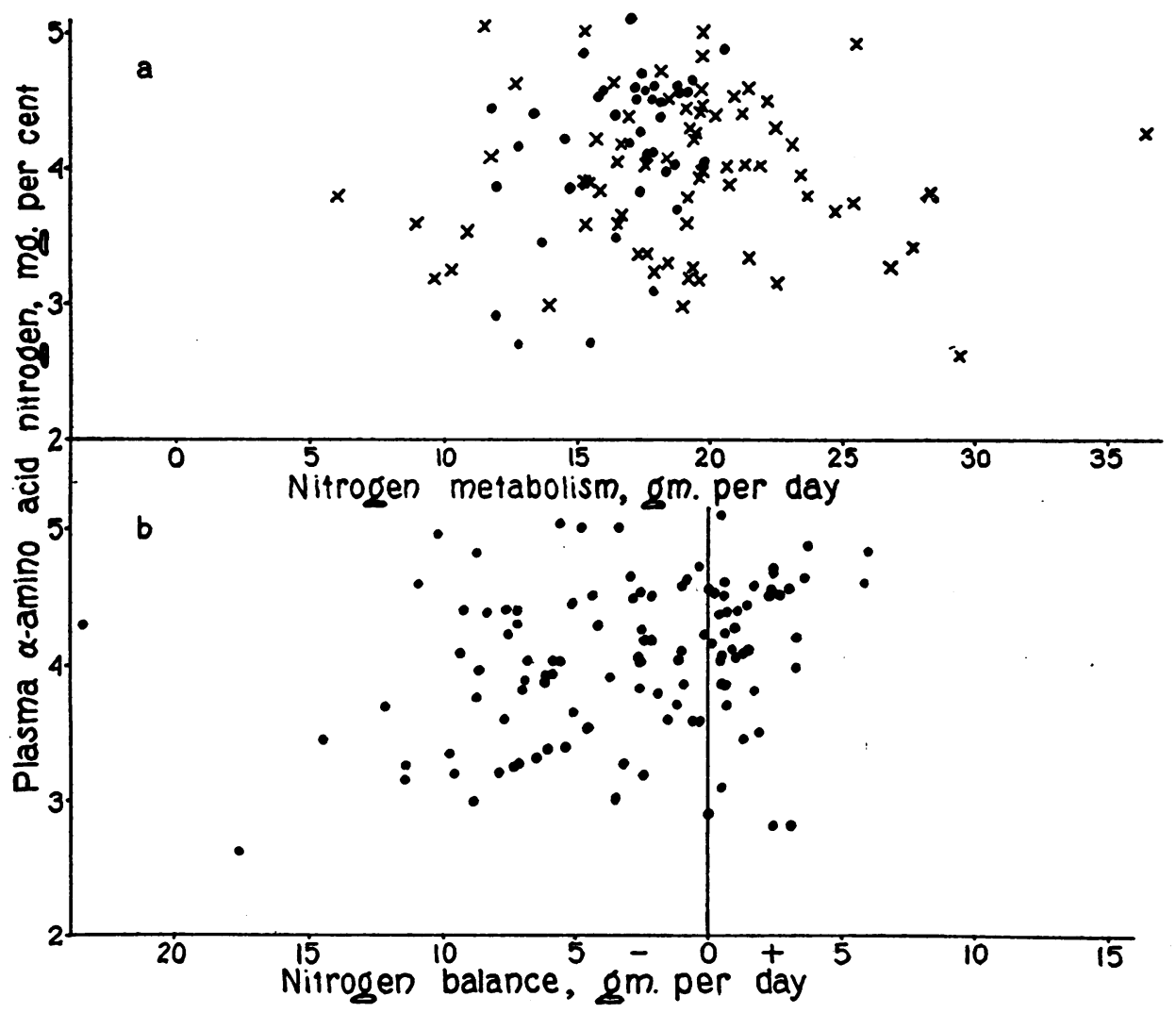

Fig. 1. (a) The Post-absorbtive Concentration of a-Amino Acids of Plasma Compared with Nitrogen Metabolism *

(b) The Post-absorbtive Concentration of a-Amino Acids of Plasma Compared with Nitrogen Balance

* Nitrogen intake or output, whichever was the larger. Circles $=$ positive, crosses $=$ negative, balances. 
TABLE I

The effect of operation on the concentration of a-amino acid nitrogen of plasma

\begin{tabular}{|c|c|c|c|c|c|c|c|c|}
\hline \multirow{3}{*}{ Number } & \multirow{3}{*}{$\begin{array}{l}\text { Physical } \\
\text { condition } \\
\text { before } \\
\text { operation }\end{array}$} & \multicolumn{6}{|c|}{ Plasma $\alpha$-amino acid nitrogen } & \multirow{3}{*}{ Recovery } \\
\hline & & \multicolumn{3}{|c|}{ Postoperative day } & & & & \\
\hline & & $\mathbf{0}$ & \multicolumn{2}{|r|}{1} & & & & \\
\hline $\begin{array}{l}\text { A83628 } \\
\text { A44427 } \\
\text { B44458 } \\
\text { B61691 } \\
\text { B53965 } \\
\text { B8104 } \\
\text { A44648 } \\
\text { B62115 } \\
34340 \\
\text { A11178 } \\
90248 \\
\text { B69089 } \\
25165 \\
\text { B68338 } \\
\text { A10607 } \\
\text { B68027 } \\
\text { A79194 } \\
\text { B62484 } \\
\text { B49302 } \\
\text { B59857 } \\
61724 \\
9093 \\
\text { B68658 } \\
\text { B69576 } \\
\text { B5775 } \\
\text { B68445 } \\
34038 \\
\text { B61943 } \\
\text { A94807 } \\
\text { B68886 } \\
\text { A36925 } \\
\text { A49273 } \\
\text { B56452 } \\
\text { B19794 } \\
\text { B58111 } \\
\text { B58721 } \\
\text { A3107 } \\
\text { B57895 } \\
91253 \\
\text { B57836 }\end{array}$ & 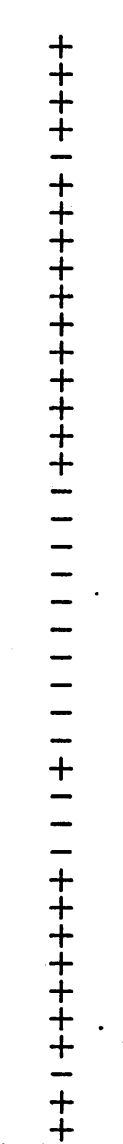 & \begin{tabular}{|c|} 
mgm. per cent \\
4.95 \\
4.85 \\
4.54 \\
4.53 \\
4.44 \\
4.44 \\
4.39 \\
4.34 \\
4.30 \\
4.24 \\
4.24 \\
4.17 \\
4.16 \\
4.16 \\
4.14 \\
3.97 \\
3.96 \\
3.94 \\
3.90 \\
3.85 \\
3.84 \\
3.73 \\
3.72 \\
3.70 \\
3.60 \\
3.51 \\
3.27 \\
3.19 \\
2.75 \\
2.51
\end{tabular} & $\begin{array}{l}{ }^{2}{ }^{m} \\
3.45 \\
4.48 \\
4.13 \\
3.97 \\
3.24 \\
3.81 \\
4.09 \\
2.71 \\
3.20 \\
3.74 \\
3.14 \\
3.64 \\
3.00 \\
3.57 \\
3.73 \\
3.42 \\
3.31 \\
3.27 \\
3.03 \\
2.94 \\
3.41 \\
3.54 \\
3.38 \\
2.93 \\
2.73 \\
3.56 \\
2.85 \\
3.04 \\
2.71 \\
2.90 \\
4.46 \\
3.19 \\
3.18 \\
4.22 \\
2.97 \\
3.59 \\
3.14 \\
3.30 \\
2.62\end{array}$ & $\begin{array}{l}\text { per cent } \\
4.17(6)^{*} \\
4.17(6) \\
4.36(2) \\
4.32(13) \\
3.37(4) \\
4.81(7) \\
3.98(4) \\
2.93(2) \\
4.08(7) \\
3.75(7) \\
4.57(2) \\
3.99(9) \\
4.22(8) \\
2.58(2) \\
3.93(3) \\
4.12(2) \\
3.51(7) \\
3.87(2) \\
3.33(2) \\
3.16(2) \\
4.61+(5) \\
3.74(8) \\
3.74(8) \\
3.31(11) \\
4.22(4) \\
4.41(2) \\
3.74(9) \\
2.93(5) \\
2.49(2) \\
4.57(9) \\
4.56(14) \\
4.54(8) \\
4.44(14) \\
4.29(7) \\
4.26(12) \\
4.11(6) \\
3.98(18) \\
3.71(12) \\
3.59(21)\end{array}$ & $\begin{array}{l}4.76(6) \\
2.98(9) \\
2.88(6)\end{array}$ & $\begin{array}{l}3.49(15) \\
2.96(4)\end{array}$ & $3.63(10)$ & 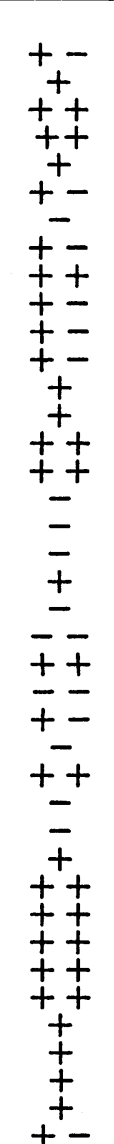 \\
\hline $\begin{array}{l}\text { Patients } \\
\text { PC 3452 } \\
\text { PC 3474 } \\
\text { PC 3477 } \\
\text { PC } 3482\end{array}$ & o had pn & \begin{tabular}{|c|}
3.85 \\
4.75 \\
4.49 \\
3.69
\end{tabular} & $\begin{array}{c}\text { grams a } \\
3.58 \\
4.26 \\
4.47 \\
4.02\end{array}$ & $\begin{array}{l}\text { took only st } \\
3.68 \text { (2) } \\
4.41 \text { (2) } \\
4.38 \text { (2) } \\
4.19 \text { (2) }\end{array}$ & $\begin{array}{l}1 \text { amounts } \\
3.68 \text { (3) } \\
4.81 \text { (3) } \\
3.60 \text { (3) }\end{array}$ & uid during $t$ & subsequent 2 & hours \\
\hline
\end{tabular}

* Figures in parentheses represent number of days after operation.

t Eggnog mixture given continuously by tube at this time.

$\ddagger 17$ days previously.

the time of operation are represented, although these are given in more detail in the protocols. A good physical condition is designated + , and a debilitated physical condition is designated - . The first 30 subjects are arranged in the descending order of the initial plasma $a$-amino acids. It is at once apparent that in general the patients with amino acid nitrogen initially above $4.0 \mathrm{mgm}$. per cent were in good physical condition before operation, while those with amino acid nitrogen below $4.0 \mathrm{mgm}$. per cent (with 1 exception, 34038) had been suffering from serious disability or injury for some time before the operative day. The 10 patients who did not have blood studies on the morning preceding the operation are arranged in the descending order of the plasma a-amino acid 
nitrogen determined during convalescence, 6 to 21 days post-operatively.

Plasma amino acid nitrogen fell during the 24 hours following operation in all but 4 of the first 30 patients. This fall is in marked contrast to the relative stability of the post-absorptive plasma amino acids of 3 normal subjects. In the course of 1 month the plasma a-amino acid nitrogens of $\mathrm{C}$. W. were $3.73,3.38,3.56$, and 3.77 ; of R. C., 4.13 , $4.21,4.30$, and 4.23 ; and of E. M., 4.07, 3.88, and $4.17 \mathrm{mgm}$. per cent. The average value for all 30 patients on the first post-operative day was 3.39 mgm. per cent of plasma a-amino acid nitrogen. Below this level fell 3 of the 10 plasma $a$-amino acid nitrogens of the 10 patients whose pre-operative levels were not estimated.

In the first 30 patients the extent of the fall was roughly proportional to the gravity of the operative procedure, except that when the amino acid nitrogen was extremely low at the onset it fell less than when it was initially high. The drop in amino acids was not large in the plasma of 6 patients who had minor operations (A10607, 90248, B68027, B44458, B61691, and A49273) and in 1 appendectomy patient, B58111. In fact, the changes in these patients are comparable with the variations in 4 patients who had pneumoencephalograms and were able to take only small amounts of fluid containing about 400 calories during the 24 hours thereafter. These values are given at the end of Table I.

In all 40 patients during recovery amino acid nitrogen rose, approaching or exceeding its preoperative concentration in the 30 patients in which this was ascertained.

The serum lipids, measured by methods previously described (9), of only 8 patients are shown in Figure 2. The ninth patient who died shortly after operation, had pronounced disease of the liver and is, therefore, omitted. In every instance the serum lipids fell after operation. In this drop, lipid phosphorus and both fractions of cholesterol were involved in every instance; the fatty acids of neutral fat, in 6 of 7 cases. The decrease was usually greater on the second than on the first day. The decrements were small, but unequivocal and consistent. In no instance did the concentration of any lipid constituent fall below the normal

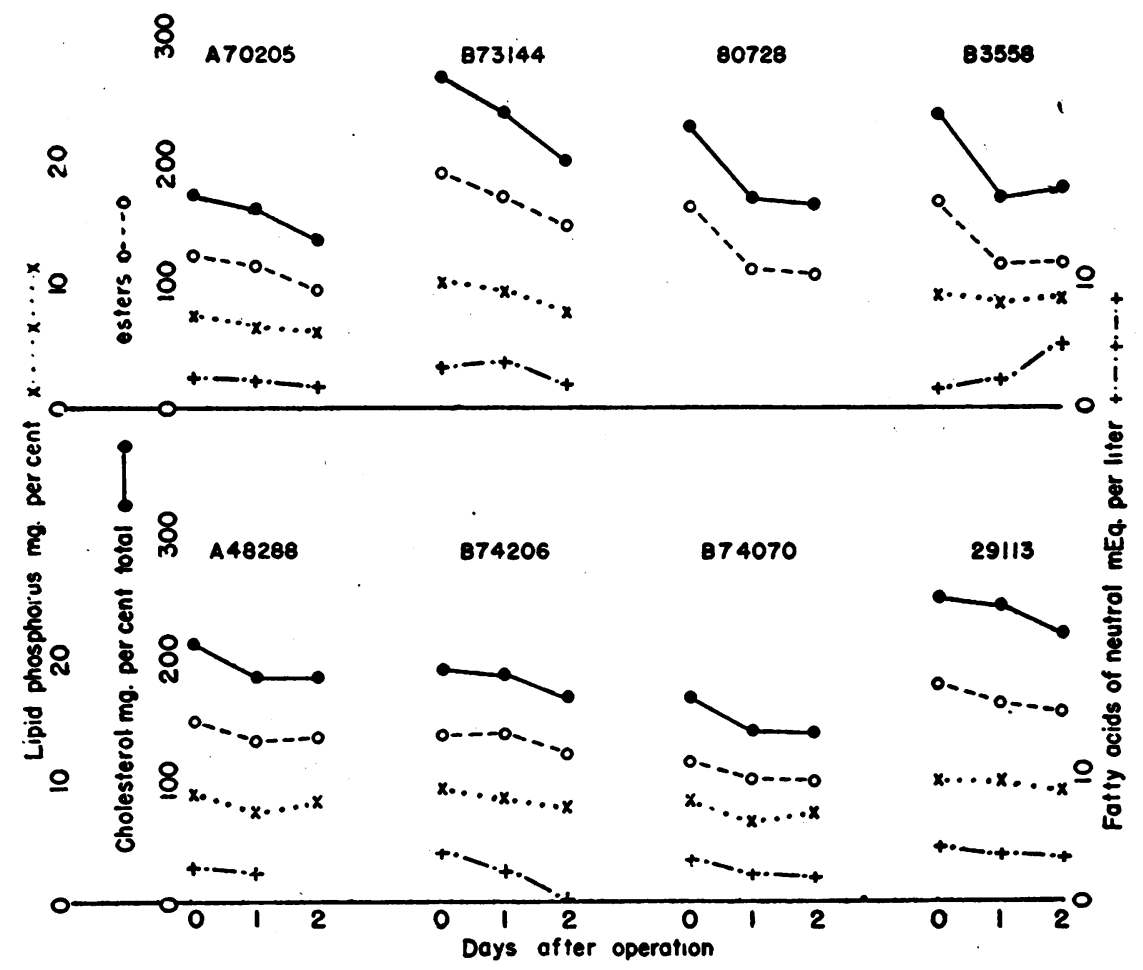

Fig. 2. Serum Lipids on Patients the Morning of Operation and on 2 Succerding MoRnings 
range of variation. Because all lipid fractions were affected, their relations to one another were not significantly disturbed. The ratio, free cholesterol: total cholesterol, on 2 occasions rose to 0.34 , just above the normal range.

\section{DISCUSSION}

The relation of the behavior of the amino acids to the conditions of the patients is best illustrated by comparisons of similiar cases. There were 7 operations on the gall bladder and bile ducts which can be compared. The initial $a$-amino acid nitrogens of B62484, B68658 and A94807, who had all been seriously ill prior to operation, were 3.94 , 3.72 , and $2.75 \mathrm{mgm}$. per cent, all below the average normal value of $4.23 \mathrm{mgm}$. per cent (7). On the other hand, A83628, A44648, and A11178, who were in good condition and free from symptoms before operation, had initial amino acid nitrogens above $4.23 \mathrm{mgm}$. per cent. The amino acids of this latter group fell sharply after operation, while those of the more chronically ill patients were but little affected. B53965 is an exception. Her initial amino acid nitrogen was high, although she was chronically ill, jaundiced and wasted. This patient, however, had definite renal insufficiency with a blood nonprotein nitrogen of $41 \mathrm{mgm}$. per cent which rose to 50 after operation. It has been reported that plasma amino acid nitrogen may be elevated in patients with advanced renal insufficiency. In addition, the amino acid nitrogen was not corrected for the elevated blood urea. In this connection it may be significant that the amino acid nitrogen of $\mathrm{B} 62115$, who had a temporary renal insufficiency as the result of a hemolytic transfusion reaction, did not fall strikingly until the second post-operative day.

The series of gastric operations affords equally good contrasts. B8104 and B62115, who were symptomless and in good condition at the time of operation, had initial plasma amino acids of 4.44 and $4.34 \mathrm{mgm}$. per cent. B59857, 9093, and $\mathrm{B} 69576$ were in deplorable states. Their amino acids were $3.85,3.73$, and $3.70 \mathrm{mgm}$. per cent. Of the hernia patients, only B68027 had low initial amino acid nitrogen. This patient also had on his forearm a carbuncle that required incision the following day.

The amino acid nitrogen of B44458 did not fall appreciably after excision of an adenofibroma of the breast under local anesthesia. On the other hand, amino acid nitrogen fell sharply from an initially normal concentration in B68338 after a radical mastectomy. In A79194, who was suffering from a recurrent fibrosarcoma of the chest wall, the amino acid nitrogen was low before operation, and fell further after a block resection. The last 2 patients, A94807 and B68886, were desperately ill before operation. Amino acid nitrogen in both was extremely low. Under these circumstances it did not fall further after operation. The low initial concentration in 34038 is quite inexplicable. The patient had been sick only 11 hours with acute appendicitis. Her post-operative course was uneventful. She differes from all the other cases also in the fact that the amino acid nitrogen of her plasma rose steadily after operation.

After injury, the duration of the amino acid nitrogen depression seems to be proportional to the severity of the operation and the post-operative course. This may be seen in the table, in which the degree of recovery at the time of the final plasma amino acid estimation has been designated in the last column. Special notes about recovery are given in the protocols, and no mention of recovery indicates that the course fell into the categories listed below. Prompt recovery in a vigorous individual was graded ++ ; satisfactory recovery accompanied by some debility was graded + ; convalescence in which the patient was holding his own, but gaining slowly, or was unable to take a full regular diet, was marked \pm ; unsatisfactory recovery was classed as - . For example, the secondary drop in A44648 was associated with a febrile reaction, the cause of which was not discovered. That the degree of recovery was associated with a rise in plasma amino acid nitrogen is indicated by the average values for the 4 recovery groups of patients. The 14 patients in the ++ group had an average final plasma $a$-amino acid nitrogen of 4.27 mgm. per cent; the 8 subjects in the + group, an average value of 4.16 ; the 8 patients in the \pm category, an average of 3.85 , and the 7 patients in the - group, a value of $3.76 \mathrm{mgm}$. per cent. Examination of individual cases with a stormy post-operative course reveals the prolongation of low levels of amino acid nitrogen until recovery progressed. Thus, B68338 was extremely ill after a radical mastectomy. Her plasma amino acids dropped from a pre-operative value of $4.16 \mathrm{mgm}$. 
per cent to 3.00 on the first post-operative day, and to 2.58 on the second post-operative day. Two days later the amino acid nitrogen had risen to 3.99 ; and 4 days thereafter, to $4.41 \mathrm{mgm}$. per cent. B49302, whose pre-operative amino acid nitrogen was $3.90 \mathrm{mgm}$. per cent, after pneumonectomy had amino acid nitrogens of 3.27 and 3.33 mgm. per cent on the first and second post-operative days. Six days after this the plasma $a$-amino acid nitrogen had risen to $4.12 \mathrm{mgm}$. per cent. B68886 was still acutely ill and febrile 6 days after operation. Her amino acid nitrogen at this time had risen slightly, but only to $2.88 \mathrm{mgm}$. per cent. A patient, B54752, not in this series, after an appendectomy, developed a fecal fistula and pneumonitis with a question of tuberculosis. For about 6 weeks he was on a daily intake of 80 to 125 grams of protein, and 3000 to 4000 calories. In spite of the fact that he was gravely ill, his nitrogen balance was slightly positive for the last week of this period. Nevertheless, his plasma $a-$ amino acid nitrogen was only $3.39 \mathrm{mgm}$. per cent at the end of this period. Two days later, when afebrile, the amino acid nitrogen was $3.95 \mathrm{mgm}$. per cent. That retarded recovery from injury is accompanied by low values of the a-amino acid nitrogen is in accordance with low values observed earlier in this study during the course of infectious diseases, and also reported by Farr and others (10) in adults with pneumococcus pneumonia. However, in infectious diseases our own measurements were not made frequently or systematically enough to establish this thesis. Hypoaminoacidemia during exacerbations of nephrosis in children has already been reported by Farr $(11,12)$.

Nitrogen balance studies were not carried out during the period of convalescence in all the patients studied. However, in a larger group of patients with infectious diseases or subjected to operation, the post-absorptive concentrations of $a$ amino acid nitrogen in the plasma have been compared with the nitrogen metabolism and with nitrogen balances (Figure 1). There was no correlation. Even when nitrogen catabolism and negative nitrogen balances were extremely large, plasma amino acid nitrogen was sometimes below normal. An example of a low amino acid after large nitrogen catabolism has been cited (B54752) in the previous paragraph as an example of low plasma amino acids with lack of. recovery. Another example of the lack of correlation between nitrogen metabolism and plasma amino acid level was afforded by a patient with lobar pneumonia (B60476). For 8 days this patient ingested 110 to 173 grams of protein and 2900 to 4200 calories. His nitrogen balance varied from -10 grams to +3.5 grams daily. His plasma amino acid nitrogen rose only from 3.75 to $4.19 \mathrm{mgm}$. per cent.

No comparison was made of the plasma amino acids and the serum proteins or serum albumins in the 30 patients who were studied pre-operatively and during recovery. However, plasma amino acids have been compared with serum albumin in the 10 patients who were studied immediately after operation and late in the recovery period, and on 23 patients with injuries or infectious diseases. No distinct relationship was apparent.

It has been generally presumed that the products of protein metabolism, both in their passage to the liver and tissues for synthesis, and to the liver and kidneys for destruction and excretion, are transported largely in the form of $a$-amino acids. It might be naturally anticipated, therefore, that the concentration of these compounds would in some measure parallel the rate of nitrogen metabolism. This does not appear to be the case. Although nitrogen metabolism is not greatly increased immediately after operation, it is not strikingly reduced. Moreover the reduction of amino acids that follows operation appears to continue throughout the subsequent period of protein wastage, even when the nitrogen catabolism is extremely large. This suggests that it may be associated with the phenomenon of "toxic destruction of protein." In this condition the whole economy of protein is profoundly disturbed. Synthetic processes appear to be in abeyance ; protein is routed to destruction. The low concentration of amino acid nitrogen in the plasma may indicate that production of urea is so active in the liver that the tissues are de ived of the amino acids required for the production of protein.

Just as patients with chronic disease or longstanding injury do not manifest the phenomenon of toxic destruction of protein, so their amino acids do not fall after operation. They are, however, initially depressed.

It was hoped that if the disorder in the injury reaction resided in the liver, evidence of damage 
to this organ might be demonstrated by characteristic disturbances of the serum lipid patterns. The fact that the serum lipids fall after operation adds 1 more item to the growing list of disorders that accompany the injury reaction. This change is not similar to that which occurs in water deprivation and starvation when the lipids increase slightly (13). The nature of the lipid disturbance cannot, however, be used to incriminate the liver, because all the lipid components are proportionally affected, while in liver disease their relations to one another are usually distorted.

\section{CONCLUSIONS}

Plasma a-amino acid nitrogen falls abruptly after injury, and remains low until recovery is well advanced, even while nitrogen catabolism is greatly increased by administration of high protein diets. The extent of the abrupt fall is directly proportional to the severity of the operative procedure, and roughly inversely proportional to the initial amino acid concentration. The latter reflects the pre-operative condition of the patient. If this is normal, the plasma $a$-amino acid nitrogen is greater than $4.0 \mathrm{mgm}$. per cent. If the patient is seriously ill before operation, the $a$-amino acid nitrogen is less than $4.0 \mathrm{mgm}$. per cent before operation. If it is already greatly reduced, it may fall no further as a result of the operation.

After injury serum lipid fractions, total and free cholesterol, lipid phosphorus and fatty acids, diminish by small but unequivocal decrements. The lipid components are proportionally affected without distortion such as occurs in liver disease.

We are grateful to the Department of Surgery for facilitating these studies on patients on their service. We express our appreciation to Miss Adelaide Kulinkowski, Miss Elsie McIntyre, Miss Catherine Marks, and Mrs.
Carol Schmitt, for their efficient services as metabolism nurses.

\section{BIBLIOGRAPHY}

1. Grossman, C. M., Sappington, T. S., Burrows, B. A., Lavietes, P. H., and Peters, J. P., Nitrogen metabolism in acute infections J. Clin. Invest., 1945, 24, 523.

2. Farr, L. E., MacFadyen, G. T., Shands, A. R., Jr., Ferguson, W. R., Dunlap, E. B., Jr., and Johnson, C., Changes in plasma amino acid nitrogen concentration following nitrous oxide and ether anesthesia and surgery. Proc. Soc. Exper. Biol. and Med., 1942, 50, 256.

3. Peters, J. P., Symposium on physiological aspects of convalescence and rehabilitation. Problems of nitrogen metabolism. Fed. Proc., 1944, 3, 197.

4. Peters, J. P., Nitrogen metabolism in acute and chronic disease. Bull. N. Y. Acad. Sc. In press.

5. Howard, J. E., Protein metabolism during convalescence after trauma. Recent studies. Arch. Surg., 1945, 50, 166.

6. Hamilton, P. B., and Van Slyke, D. D., The gasometric determination of free amino acids in blood filtrates by the ninhydrin-carbon dioxide method. J. Biol. Chem., 1943, 150, 231.

7. Woodruff, C. W., and Man, E. B., Concentration of a-amino acid nitrogen in plasma of normal subjects. J. Biol. Chem., 1945, 157, 93.

8. Peters, J. P., To be published.

9. Peters, J. P., and Man, E. B., The interrelation of serum lipids in normal persons. J. Clin. Invest., 1943, 22, 707.

10. Farr, L. E., McCarthy, W. C., and Francis, T., Jr., Plasma amino-acid levels in health and in measles, scarlet fever and pneumonia. Am. J. M. Sc., 1942, 203, 668.

11. Farr, L. E., and MacFadyen, D. A., Hypoaminoacidemia in children with nephrotic crises. Am. J. Dis. Child., 1940, 59, 782.

12. Farr, L. E., The significance of protein metabolism in the nephrotic child. J. Pediat., 1940, 17, 734.

13. Kartin, B. L., Man, E. B., Winkler, A. W., and Peters, J. P., Blood ketones and serum lipids in starvation and water deprivation. J. Clin. Invest., 1944, 23, 824. 